\title{
PURIFICAÇÃO DA ENZIMA DEXTRANA-SACARASE A PARTIR DE Leuconostoc pseudomesenteroides
}

\author{
$\underline{\text { Isabela Souza Coccorese }}^{1}$; Claudio Roberto Nobrega Amorim ${ }^{2}$ \\ 1. Bolsista PROBIC/UEFS, Graduando em Bacharelado em Ciências Biológicas, Universidade Estadual de Feira de \\ Santana, e-mail: isabelauefs@ hotmail.com \\ 2. Claudio Roberto Nobrega Amorim, Departamento de Ciências Biológicas, Universidade Estadual de Feira de \\ Santana, e-mail: amorim@uefs.com.br
}

PALAVRAS-CHAVE: Purificação; Dextrana-sacarase;Leuconostoc.

\section{INTRODUÇÃO}

A Dextrana é um dos exopolissacarídeos de maior importância industrial, largamente utilizada como aditivo, espessante, estabilizante e emulsificante em produtos alimentícios, cosméticos, imobilizante em processos cromatográficos, e também na área médica, agindo como anticoagulante e extensor de plasma, dentre outros (Bhavani\&Nisha, 2010).

Muito empenho tem sido aplicado ao longo dos anos para desenvolver metodologias eficazes, rápidas e com menor custo para a produção das dextranas (Nigam et al., 2006); (Vettori et al., 2012). Assim, os estudos que se voltam para a dextranasacarase têm um papel fundamental neste processo, principalmente, os que focam na purificação da enzima, cujo emprego na produção do polissacarídeo livre de células é um promissor campo quase inexplorado da indústria (Fattah et al., 2012). Dentre os benefícios desta abordagem, pode-se frisar a redução com gastos para manter a colônia, facilidade na separação final do produto com alto grau de pureza, além da possibilidade de reaproveitamento da enzima nas etapas da produção (Chiellini et al., 2001). O objetivo deste trabalho foi isolar e purificar a enzima dextrana-sacarase a partir da linhagem nativa R2 de Leuconostoc pseudomesenteroides.

\section{MATERIAL E MÉTODOS OU METODOLOGIA (ou equivalente)}

As amostras bacterianas produtoras de exopolissacarídeos a partir da sacarose utilizadas neste estudo foram cedidas gentilmente pela Prof ${ }^{a}$. Dra. Elinalva Maciel Paulo, Coordenadora do LAMASP - Laboratório de Microbiologia Aplicada à Saúde Pública da Universidade Estadual de Feira de Santana (UEFS). Tais amostras foram triadas e isoladas conforme a metodologia descrita por Paulo et al. (2012), a partir de produtos alimentícios industrializados (laticínios) e vegetais obtidos de produtores da região de Feira de Santana-BA.

As colônias da linhagem nativa R2 de Leuconostoc pseudomesenteroides foram cultivadas em meio MRS Agar modificado, suplementado com sacarose em vez de glicose (Goyal\&Katiyar, 1996), com pH 6.7, sob temperatura de $23^{\circ} \mathrm{C}$ com agitação, durante 72 horas. Após, foi verificada a atividade metabólica das bactérias sobre o substrato em diferentes concentrações nos meios de cultura. Foram otimizadas as condições de cultivo, sendo em seguida retiradas alíquotas de $2 \mathrm{ml}$ do meio para 
conservação do microorganismo em solução de glicerol a 20\% e mantidas em freezer à $20^{\circ} \mathrm{C}$, e outra parte foi crescida em meio otimizado para produção da dextrana-sacarase.

Após o crescimento da bactéria, o cultivo foi centrifugado a $4.000 \mathrm{rpm}$ por 10 minutos e o sobrenadante coletado. Foi adicionado o polietilenoglicol (PEG) préarrefecido a $0^{\circ} \mathrm{C}$ a $200 \mathrm{ml}$ do sobrenadante isento de células para se obter as concentrações finais de 20, 25, 33, 40 e 50 (\%, $\mathrm{v} / \mathrm{v})$. Estas frações foram analisadas quanto à concentração proteica e submetidas à diálise utilizando um filtro com porosidade de $5 \mathrm{kDa}$. (Contiero, 2004).

O material dialisado foi aplicado a uma coluna de cromatografia de $600 \times 15 \mathrm{~mm}$ (Figura 1) utilizando a resina Sepharose CL-4B, eluída com tampão acetato de sódio $20 \mathrm{mM}$, pH 6,7. Foram coletadas frações de $5 \mathrm{~mL}$ em tubos de ensaio, que foram lidas em espectrofotômetro num comprimento de onda de $280 \mathrm{~nm}$ para a detecção da proteína (Goldfarb et al., 1951) (Figura 2).

\section{RESULTADOS E/OU DISCUSSÃO (ou Análise e discussão dos resultados)}

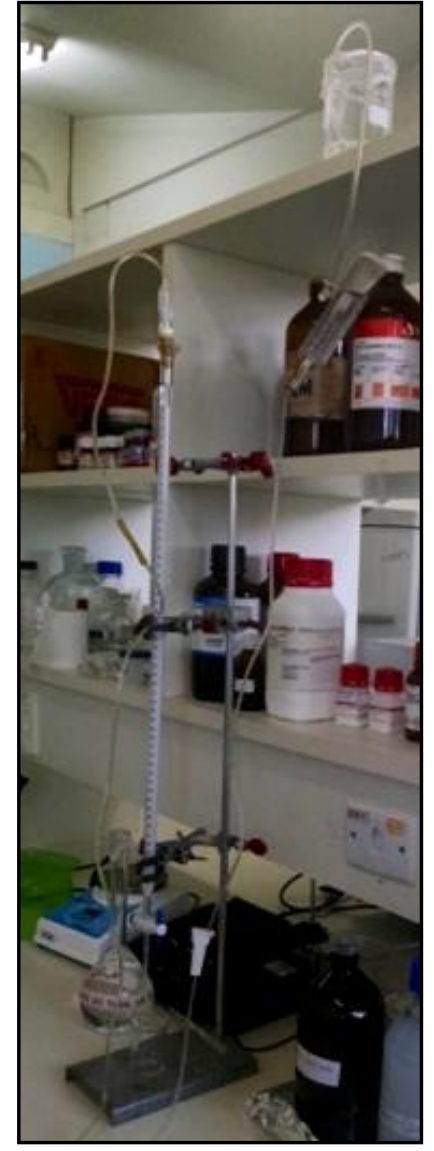

Figura 1 - Coluna de cromatografia em operação.

Na primeira corrida aplicada na coluna de cromatografia foram coletados 25 tubos com as frações; na segunda, 15; e na terceira 24 tubos.

Os perfis de eluição mostraram o aparecimento de picos que se concentraram em duas regiões. A primeira região foi percebida claramente em todas as corridas, mas a terceira corrida $(\mathrm{N})$ foi a que mostrou melhor as duas regiões de pico. A análise dos picos de eluição permite sugerir a presença de várias proteínas nas amostras, provavelmente a partir do extrato bruto do meio de cultura, as frações não eluíram separadamente,

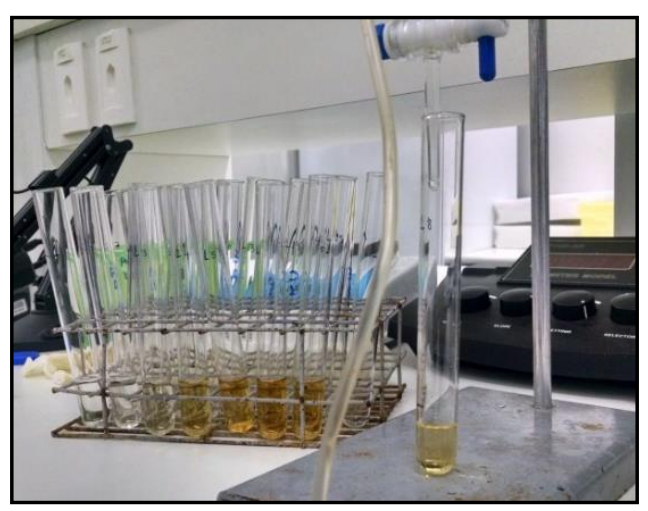

Figura 2 - Eluição da solução concentrada através da coluna de Sepharose CL - 4B refletindo um resultado de baixa resolução (Figura 3). A concentração de picos em duas regiões diferentes pode indicar a presença de dextrana-sacarase em pelo menos um deles.

A quantidade medida de proteína por UV $280 \mathrm{~nm}$ de comprimento de onda revelou absorbâncias com uma grande variação; as duas regiões apresentaram valores de 1,627 - 1,523 unidades de absorbância (UA) na primeira região e 0,025 - 0,033 UA na segunda região (Tabela 1). 


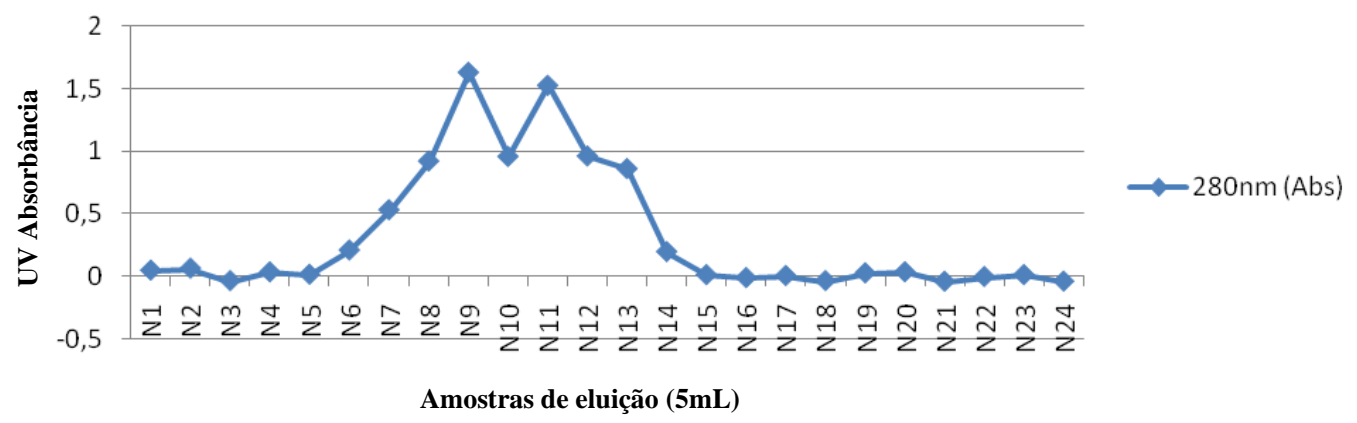

Figura 3 - Perfil de eluição de proteínas na coluna de Sepharose

Tabela 1. A absorbância de luz ultravioleta a um comprimento de onda de $280 \mathrm{~nm}$ nas amostras eluídas a partir de três passagens cromatográficas

\begin{tabular}{|c|c|c|c|c|c|}
\hline Amostras & $\begin{array}{c}280 \mathrm{~nm} \\
(\mathrm{Abs})\end{array}$ & Amostras & $\begin{array}{c}280 \mathrm{~nm} \\
(\mathrm{Abs})\end{array}$ & Amostras & $\begin{array}{r}280 \mathrm{~nm} \\
(\mathrm{Abs})\end{array}$ \\
\hline L1 & 0,025 & M1 & 0,022 & N1 & 0,046 \\
\hline $\mathbf{L} 2$ & 0,128 & M2 & 0,015 & $\mathbf{N} 2$ & 0,062 \\
\hline $\mathbf{L 3}$ & 0,695 & M3 & 0,015 & N3 & $-0,038$ \\
\hline L4 & 0,999 & M4 & 0,134 & N4 & 0,032 \\
\hline L5 & 1,402 & M5 & 0,47 & N5 & 0,013 \\
\hline L6 & 1,061 & M6 & 0,798 & N6 & 0,207 \\
\hline L7 & 0,964 & M7 & 1,001 & N7 & 0,529 \\
\hline L8 & 0,917 & M8 & 1,045 & N8 & 0,918 \\
\hline L9 & 0,07 & M9 & 0,942 & N9 & 1,627 \\
\hline L10 & $-0,023$ & M10 & 0,473 & N10 & 0,955 \\
\hline L11 & $-0,014$ & M11 & $-0,017$ & N11 & 1,523 \\
\hline L12 & $-0,005$ & M12 & $-0,024$ & N12 & 0,959 \\
\hline L13 & $-0,015$ & M13 & $-0,025$ & N13 & 0,858 \\
\hline L14 & $-0,03$ & M14 & $-0,014$ & N14 & 0,194 \\
\hline L15 & 0,007 & M15 & $-0,042$ & N15 & 0,01 \\
\hline L16 & $-0,028$ & & & N16 & $-0,014$ \\
\hline L17 & $-0,004$ & & & N17 & 0,003 \\
\hline L18 & $-0,029$ & & & N18 & $-0,038$ \\
\hline L19 & $-0,065$ & & & N19 & 0,025 \\
\hline L20 & $-0,021$ & & & $\mathbf{N} 20$ & 0,033 \\
\hline L21 & $-0,006$ & & & N21 & $-0,043$ \\
\hline L22 & $-0,029$ & & & N22 & $-0,005$ \\
\hline $\mathbf{L 2 3}$ & $-0,007$ & & & $\mathbf{N} 23$ & 0,01 \\
\hline L24 & 0,011 & & & N24 & $-0,042$ \\
\hline L25 & 0,001 & & & & \\
\hline
\end{tabular}

Legenda: $\mathrm{L}=$ primeira corrida cromatográfica de eluição realizada na coluna. $\mathrm{M}=$ segunda corrida. $\mathrm{N}=$ terceira corrida. 


\section{CONSIDERAÇÕES FINAIS (ou Conclusão)}

Os resultados obtidos na cromatografia não foram bons e espera-se que novos experimentos que avaliam outros métodos de concentração de meio de caldo, tais como liofilização, irão facilitar a obtenção da fração de proteína e reduzir as perdas de material durante o processo. Espera-se também que utilize outra resina de cromatografia, pois assim, com um campo de resolução diferente possa melhorar o perfil de separação.

\section{REFERÊNCIAS}

BHAVANI, A. Lakshmi; NISHA, J. Dextran - The Polysaccharide With Versatile Uses. Int J Pharm Biol Sci, v. 1, n. 4, p. 569-573, 2010.

CHIELLINI, Emo et al. Biomedical Polymers: Sustainable Polymer Science And Technology. ISBN 0-306-46652-X. 2001.

CONTIERO, J. Estudo Da Produção De Dextrana sacarase Por Leuconostoc mesenteroidesFt 045 B, Tese de doutorado. Universidade Estadual Júlio de Mesquita Filho, Rio Claro - São Paulo. 2004.

FATTAH, Ahmed F. Abdel et al. Production And Properties Of Dextransucrase By Free And Immobilized Cells Of Leuconostoc paramesenteroides. Egypt Pharmaceut J, v. 11, n. 1, p. 42, 2012.

GOLDFARB, A. Robert et al. The ultraviolet absorption spectra of proteins. J Biol Chem,v. 193, p. 397-404, 1951.

GOYAL, A.; KATIYAR, S.S. Regulation Of Dextransucrase Productivity Of Leuconostoc mesenteroides NRRL B-512F By The Maintenance Media. J. Gen. Appl. Microbiol., v. 42, n. 1, p. 81-85, 1996.

JEANES, A. et al. Characterization And Classification Of Dextrans From Ninety-Six Strains Of Bacteria. J. Am. Chem. Soc., v. 76, n. 20, p. 5041-5052, 1954.

NIGAM, M.; GOYAL, A.; KATIYAR, S.S. High Yield Purification Of Dextransucrase From Leuconostoc mesenteroidesNrrl B-512f ByPhasePartitioning. J. Food. Biochem., v. 30, n. 1, p. 12-20, 2006.

PAULO, E. M. et al. Na Alternative Method For Screening Lactic Acid Bacteria For The Production Of Exopolysaccharides With Rapid Confimation. Ciênc. Tecnol. Aliment. (Campinas) v. 32, n. 4, 2012.

PAULO, E. M. et al. Production, Extraction And Characterization Of Exopolysaccharides Produced By The Native Leuconostoc pseudomesenteroides R2 Strain. An. Acad. Bras. Ciênc. v.84 n. 2, 2012.

ROBYT, John. F. Mechanism In The Glucansucrase Synthesis Of Polysaccharides And Oligosaccharides From Sucrose. Adv Carbohyd Chem Bi, San Diego, v. 51, p. 133-168, 1995. VETTORI, et al. Dextran: Effect Of Process Parameters On Production, Purification And Molecular Weight And Recent Applications. Diálogos Ciênc. 31, 171-186.2012. 